Check for updates

Cite this: Org. Biomol. Chem., 2021, 19, 8232

Received 28th July 2021,

Accepted 26th August 2021

DOI: 10.1039/d1ob01479j

rsc.li/obc

\section{Deuteration of terminal alkynes realizes simultaneous live cell Raman imaging of similar alkyne-tagged biomolecules $\uparrow$}

\author{
Syusuke Egoshi, (D) ${ }^{a}$ Kosuke Dodo, (D) *a,b Kenji Ohgane (iD a and Mikiko Sodeoka (ID *a,b
}

\begin{abstract}
Alkynes were employed as tags to observe small molecules in cells by Raman microscopy. Herein, simple deuteration was found to shift the vibrational frequency of the alkyne by $135 \mathrm{~cm}^{-1}$. Twocolor Raman imaging of $\mathrm{D}$-alkynes and $\mathrm{H}$-alkynes made it possible to distinguish between and observe similar small molecules in live cells.
\end{abstract}

Raman microscopy is a powerful imaging tool for observing endogenous biomolecules, as it can detect molecular vibrations in cells without exogenous labeling. ${ }^{1}$ However, cells contain many molecules and display complicated Raman spectra, making label-free Raman imaging of target molecules difficult. To overcome this limitation, several functional groups have been used as Raman tags, including alkynes $(\mathrm{C} \equiv \mathrm{C})$, nitriles $(\mathrm{C} \equiv \mathrm{N})$, and carbon-deuterium $(\mathrm{C}-\mathrm{D})$ bonds. $^{2-6}$

The carbon-carbon triple bond of alkynes exhibits an intense Raman signal in a Raman-silent region (1800-2600 $\mathrm{cm}^{-1}$ ) that is free of interference from natural cellular molecules. Alkynes can be introduced without affecting the biological activities of small molecules and can be selectively detected using a Raman microscope with the technique referred to as alkyne-tag Raman imaging (ATRI). ${ }^{2,7}$ Since ATRI was first established by Sodeoka et al. in 2011, various alkyne tags (e.g., diynes, ${ }^{3,8-11}{ }^{13} \mathrm{C}$-labeled alkynes, ${ }^{12}$ and gem-difluoroalkynes ${ }^{13}$ ) have been developed to observe biomolecules.

Since D is twice as heavy as $\mathrm{H}$, the Raman scattering of the molecules was significantly affected by deuteration. In fact, C$\mathrm{H}$ bond stretching frequencies of alkanes and alkenes appear in the region of $2650-3050 \mathrm{~cm}^{-1}$, while their corresponding CD stretching frequencies appear in the region of 2050-2250 $\mathrm{cm}^{-1}$ (e.g., ethanol and ethanol- $d_{6}$, Fig. 1a). ${ }^{14}$

${ }^{a}$ Synthetic Organic Chemistry Laboratory, RIKEN Cluster for Pioneering Research, 2-1 Hirosawa, Wako, Saitama 351-0198, Japan.E-mail: dodo@riken.jp, sodeoka@riken.jp

${ }^{b}$ RIKEN Center for Sustainable Resource Science, 2-1, Hirosawa, Wako, Saitama 3510198, Japan

$\dagger$ Electronic supplementary information (ESI) available: Experimental procedures, supplemental data, and spectral data. See DOI: 10.1039/d1ob01479j
Deuteration also affects the vibrational frequency of the $\mathrm{C}=\mathrm{C}$ bond, which shifts by approximately 20 to $30 \mathrm{~cm}^{-1}$ (e.g., $1654 \mathrm{~cm}^{-1}$ for 3-cis-hexene and $1632 \mathrm{~cm}^{-1}$ for 3-cis-hexene-3,4$d_{2}$, Fig. 1b). ${ }^{15}$ We recently reported Raman imaging of deuterated $\gamma$-linolenic acid based on the deuterated $\mathrm{C}=\mathrm{C}$ stretching signal. ${ }^{16}$ Therefore, we anticipated that the $\mathrm{C} \equiv \mathrm{C}$ vibrational frequency also shifts upon deuteration; deuterated alkynes

a)

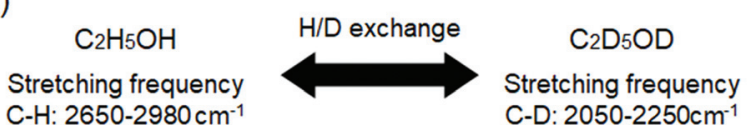

b)
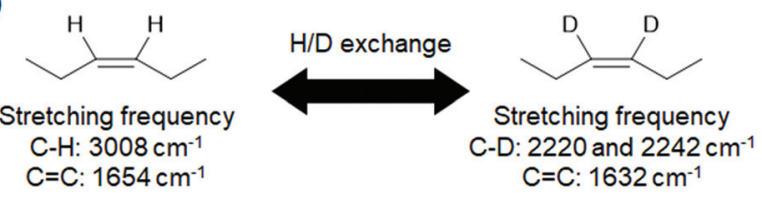

c)

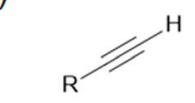

Stretching frequency $\mathrm{C} \equiv \mathrm{C}: 2120 \mathrm{~cm}^{-1}$
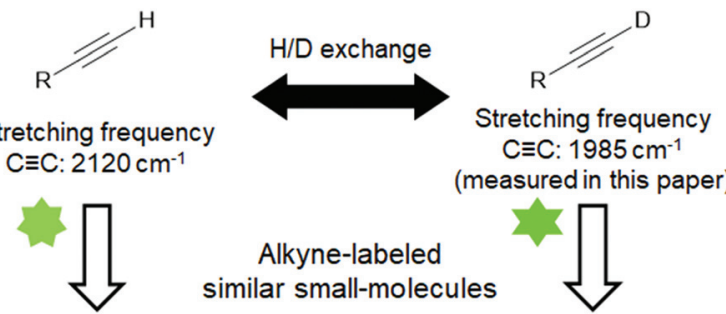

\section{Alkyne-labeled similar small-molecules}
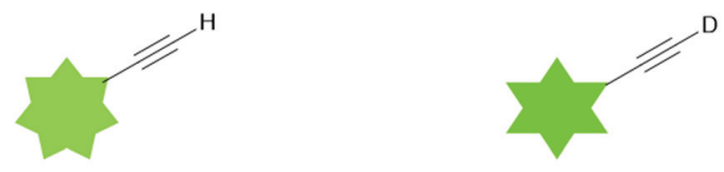

Localized position of each molecule can be detected by Raman microscopy

Fig. 1 The effect of deuteration on stretching frequencies detected by Raman microscopy. Comparison of the vibrational frequencies between (a) methanol and methanol- $d_{6}$ and (b) cis-hexene and cis-hexene-3,4$d_{2}$. (c) Application of D-labeled alkynes for two-color Raman imaging. 
(D-alkynes) are expected to offer new tags for live cell Raman imaging (Fig. 1c). Our hypothesis was further supported by the density functional theory (DFT) calculations at the B3LYP/6$31 \mathrm{G}^{*}$ level. The calculated $\mathrm{C} \equiv \mathrm{C}$ vibrational frequency of 1-hexyne is red-shifted by $148 \mathrm{~cm}^{-1}$ upon deuteration (from $2120 \mathrm{~cm}^{-1}$ to $1972 \mathrm{~cm}^{-1}$ ). This value is much larger than those observed in the replacement of the alkyne carbons with ${ }^{13} \mathrm{C}$ (e.g., $48 \mathrm{~cm}^{-1}$ for mono- ${ }^{13} \mathrm{C}$-alkyne and $77 \mathrm{~cm}^{-1}$ for $\mathrm{di}^{-}{ }^{13} \mathrm{C}$ alkyne). ${ }^{12}$ Herein, we demonstrate the potential of D-alkynes as Raman tags for live cell Raman imaging.

First, to determine the potential of D-alkynes as Raman tags, we examined their physical and chemical properties. D-alkynes were synthesized by the treatment of H-alkynes in heavy water $\left(\mathrm{D}_{2} \mathrm{O}\right)$ containing strong bases. ${ }^{17,18}$ We synthesized deuterated 6-heptyn-1-ol (D-1) from 1 as a non-conjugated terminal alkyne and deuterated 4-ethynylbenzyl alcohol (D-2) from 2 as a conjugated terminal alkyne using the procedure shown in Scheme 1. High incorporation of D $(>99 \%$, determined by ${ }^{1} \mathrm{H}$-NMR spectroscopy) was achieved by repeating the same reaction three times (Scheme 1). 1 exhibited an alkynyl $\mathrm{C}-\mathrm{H}$ stretch at $3304 \mathrm{~cm}^{-1}$ and D-1 displayed an alkynyl C-D stretch at $2595 \mathrm{~cm}^{-1}$ (Fig. S1a $\dagger$ ). In addition, 2 exhibited alkynyl C-H stretches at $3268 \mathrm{~cm}^{-1}$ and $3289 \mathrm{~cm}^{-1}$, and D-2 displayed alkynyl C-D stretches at $2575 \mathrm{~cm}^{-1}$ and $2585 \mathrm{~cm}^{-1}$ (Fig. S1b†). However, the Raman intensity of the $\mathrm{C}-\mathrm{H} / \mathrm{C}-\mathrm{D}$ stretching frequencies was too weak to be observed in cells. In addition, the $\mathrm{C}-\mathrm{H}$ stretching frequency was difficult to detect in aqueous solutions because the Raman signal of water appears as a broad peak from $2800 \mathrm{~cm}^{-1}$ to $3800 \mathrm{~cm}^{-1}$. ${ }^{19}$

On the other hand, the effect of deuteration on the $\mathrm{C} \equiv \mathrm{C}$ vibrational frequency was very interesting. Upon deuteration, the $\mathrm{C} \equiv \mathrm{C}$ vibrational frequency of 1 shifted from $2119 \mathrm{~cm}^{-1}$ to $1985 \mathrm{~cm}^{-1}$ (D-1), while that of 2 also shifted similarly from $2110 \mathrm{~cm}^{-1}$ to $1974 \mathrm{~cm}^{-1}$ for D-2 (Fig. S1†). These changes are more pronounced than those from the deuteration of alkenes $\left(\sim 20 \mathrm{~cm}^{-1}\right)$. The Raman peak area ratio corresponding to deuterated and protonated $\mathrm{C} \equiv \mathrm{C}(<0.01)$ was in good agreement with the ratio estimated by ${ }^{1} \mathrm{H}-\mathrm{NMR}$ analysis (Fig. $\mathrm{S} 1 \uparrow$ and $\left.{ }^{1} \mathrm{H}-\mathrm{NMR}\right)$. Furthermore, strong correlations between the molar ratios of the $\mathrm{H}$-/D-alkynes and the Raman peak area
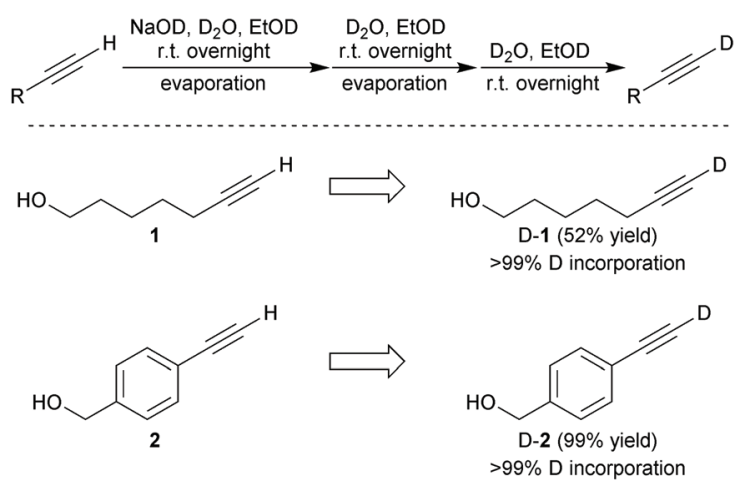

Scheme 1 Synthesis of D-alkynes (D-1 and D-2) with high D incorporation. ratios of the H-/D-alkynes were confirmed (Fig. S2 $\dagger$ ). These results indicate that the real-time $\mathrm{H} / \mathrm{D}$ exchange of terminal alkynes can be quantitatively evaluated by Raman microscopy. Moreover, the difference in vibrational frequencies was approximately $135 \mathrm{~cm}^{-1}$ between the $\mathrm{H}$-/D-alkynes, even though they are nearly identical in structure. We therefore speculated that H-/D-alkynes could be employed as Raman tags to distinguish between and observe similar alkyne-tagged small molecules in cells.

In order to pursue the use of H-/D-alkynes in cells, we first verified the stability of the $\mathrm{D}$-alkynes by measuring the timecourse Raman spectra in phosphate buffer ( $\mathrm{pH} 6.0,7.0$, or 8.0) containing $20 \mathrm{mM} \mathrm{D-1}$ or D-2 at $37{ }^{\circ} \mathrm{C}$. Surprisingly, D/H exchange of the D-alkynes was observed at every $\mathrm{pH}$. Moreover, conjugated D-2 reacted faster than non-conjugated D-1 (Fig. 2). The $\mathrm{C} \equiv \mathrm{C}$ Raman peak of $\mathrm{D}-\mathbf{1}$ disappeared under slightly alkaline conditions after $8 \mathrm{~h}$ at $\mathrm{pH}$ 8.0. After $12 \mathrm{~h}$ at neutral $\mathrm{pH}$, more than $40 \%$ of the $\mathrm{C} \equiv \mathrm{C}$ signal of $\mathrm{D}-1$ remained. At slightly acidic $\mathrm{pH}$ ( $\mathrm{pH} 6.0$ ), more than $90 \%$ of the original $\mathrm{C} \equiv \mathrm{C}$ signal was observed after $12 \mathrm{~h}$ (Fig. 2a). Conversely, the $\mathrm{C} \equiv \mathrm{C}$ Raman peak of D-2 was not detected after only $1 \mathrm{~h}$ at $\mathrm{pH} 8.0$ and after $4 \mathrm{~h}$ at $\mathrm{pH}$ 7.0. At $\mathrm{pH} 6.0$, only $20 \%$ of the original $\mathrm{C} \equiv \mathrm{C}$ signal remained after $12 \mathrm{~h}$ (Fig. 2b). Furthermore, we found that $\mathrm{D} / \mathrm{H}$ exchange of the D-alkynes at $\mathrm{pH} 7.0$ depends on the temperature of the solution (Fig. S3†). These results suggest that nonconjugated D-alkynes under neutral or acidic conditions can be employed as Raman tags in cells.

We also investigated the $\mathrm{H} / \mathrm{D}$ exchange from the $\mathrm{H}$-alkynes to the D-alkynes in deuterated buffer. The buffer $\mathrm{pD}$ was
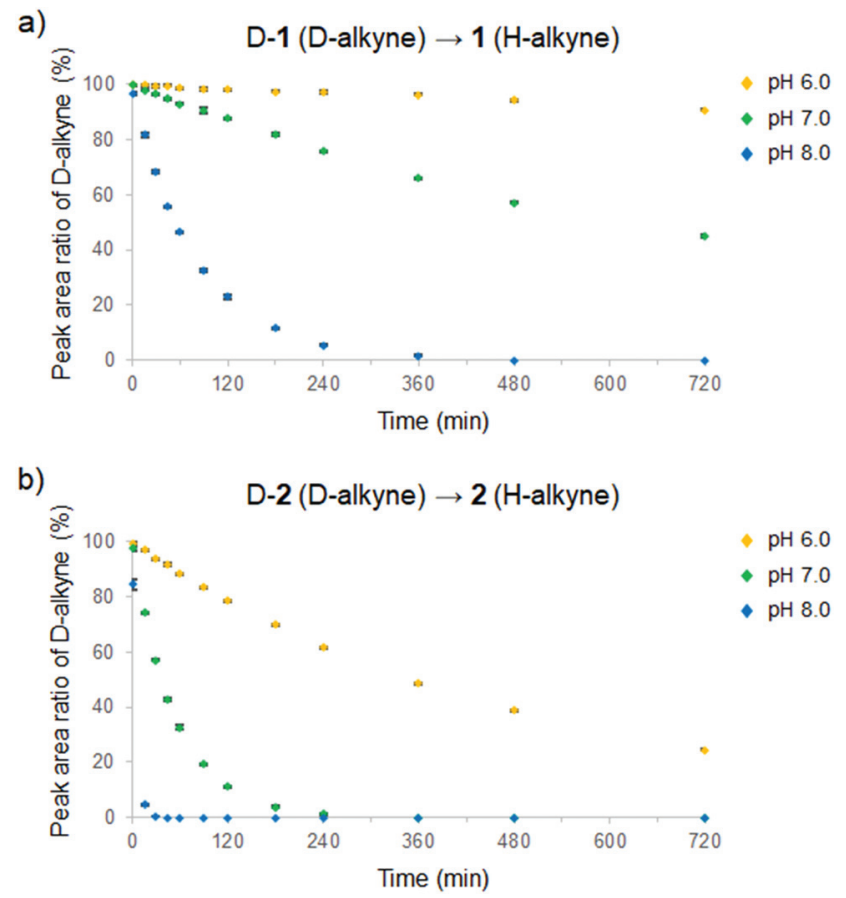

Fig. 2 Real-time analysis of $\mathrm{D} / \mathrm{H}$ exchange from $\mathrm{D}$-alkynes to $\mathrm{H}$-alkynes at various $\mathrm{pH}(6.0-8.0)$ in phosphate buffer at $37^{\circ} \mathrm{C}$ of (a) D-1 and (b) D-2. Data are presented as mean \pm SD $(n=3)$. 
Table 1 Apparent $\mathrm{D} / \mathrm{H}$ exchange rate constants $\left(\mathrm{min}^{-1}\right)$ from $\mathrm{D}$-alkyne to $\mathrm{H}$-alkyne in phosphate buffer ${ }^{a}$

\begin{tabular}{lllll}
\hline $\mathrm{pH}$ & ${ }^{\circ} \mathrm{C}$ & $\mathrm{OH}^{-b}$ & D-1 to 1 & D-2 to 2 \\
\hline 6.0 & 37 & $2.32 \times 10^{-8}$ & $(1.26 \pm 0.005) \times 10^{-4}$ & $(1.97 \pm 0.005) \times 10^{-3}$ \\
7.0 & 4 & $1.86 \times 10^{-8}$ & $(1.49 \pm 0.03) \times 10^{-5}$ & $(1.26 \pm 0.007) \times 10^{-4}$ \\
& 20 & $6.50 \times 10^{-8}$ & $(1.05 \pm 0.005) \times 10^{-4}$ & $(1.69 \pm 0.003) \times 10^{-3}$ \\
& 37 & $2.32 \times 10^{-7}$ & $(1.16 \pm 0.01) \times 10^{-3}$ & $(1.84 \pm 0.01) \times 10^{-2}$ \\
8.0 & 37 & $2.32 \times 10^{-6}$ & $(1.17 \pm 0.02) \times 10^{-2}$ & $(1.94 \pm 0.02) \times 10^{-1}$
\end{tabular}

${ }^{a}$ Obtained from data in Fig. 2 and $\mathrm{S}_{3} \dagger^{b}$ The value $\left(\mathrm{mol} \mathrm{L}^{-1}\right)$ of $\left[\mathrm{OH}^{-}\right]$ was calculated according to ref. 21.

adjusted according to $\mathrm{pD}=\mathrm{pH}+0.41 .^{20}$ As a result, H/D exchange of the $\mathrm{H}$-alkynes was also observed at all $\mathrm{pD}$, with 2 reacting faster than $\mathbf{1}$ (Fig. $\mathrm{S} 4 \dagger$ ) in the same manner as D-1 and D-2. We then calculated the apparent rate constants for $\mathrm{D} / \mathrm{H}$ and $\mathrm{H} / \mathrm{D}$ exchange of the terminal alkynes (Tables 1 and 2). As the $\mathrm{pH} / \mathrm{pD}$ value increases by 1.0 or the temperature increases by $\sim 15{ }^{\circ} \mathrm{C}$, the rate constants increase by an order of magnitude. Furthermore, $\mathrm{D} / \mathrm{H}$ exchange in the $\mathrm{pH}$ buffer was faster than $\mathrm{H} / \mathrm{D}$ exchange in $\mathrm{pD}$ buffer of the same value. These results indicate that the $\mathrm{D} / \mathrm{H}$ or $\mathrm{H} / \mathrm{D}$ exchange rate strongly depends on the amount of $\left[\mathrm{OH}^{-}\right]$or $\left[\mathrm{OD}^{-}\right]$in the buffer. A proportional relationship exists between the $\mathrm{D} / \mathrm{H}$ or $\mathrm{H} / \mathrm{D}$ exchange rate constants and the amount of $\left[\mathrm{OH}^{-}\right]$or $\left[\mathrm{OD}^{-}\right]$in each buffer, which were calculated from the $\mathrm{p} K_{\mathrm{w}}$ values at several temperatures. ${ }^{21}$ Theoretically, the calculated amount of $\left[\mathrm{OH}^{-}\right]$should be 10 times higher than the amount of $\left[\mathrm{OD}^{-}\right]$for the same $\mathrm{pH}$ and $\mathrm{pD}$ values, and thus expected $\mathrm{D} / \mathrm{H}$ exchange rate constants could be 10 times higher than that of H/D exchange. However, the reaction rate constants of $\mathrm{D} / \mathrm{H}$ exchange differed from the rate constants of $\mathrm{H} / \mathrm{D}$ exchange by a factor of approximately three in our experiments (Tables 1 and 2). This difference can be attributed to the slower D/H exchange of the D-alkynes than H/D exchange of the $\mathrm{H}$-alkynes, presumably due to the kinetic isotope effect (KIE) of deuterium.

To demonstrate Raman imaging of D-alkynes in live cells, we next turned our attention to long-chain fatty acids (FAs). Saturated FAs (SFAs) exhibit different intracellular metabolism/distribution from unsaturated FAs (UFAs), even with chains of the same carbon number. For example, the C18 SFA octadecynoic acid (3) exhibits a cytoplasmic distribution after accumulating in lipid droplets (LDs), ${ }^{12}$ whereas the C18 UFA oleic acid (4) remains accumulating in $\mathrm{LDs}^{22}$ In order to

Table 2 Apparent $\mathrm{H} / \mathrm{D}$ exchange rate constants $\left(\mathrm{min}^{-1}\right)$ from $\mathrm{H}$-alkyne to $\mathrm{D}$-alkyne in deuterated phosphate buffer at $37^{\circ} \mathrm{C}^{a}$

\begin{tabular}{llll}
\hline pD & OD $^{-b}$ & 1 to D-1 & 2 to D-2 \\
\hline 6.0 & $2.66 \times 10^{-9}$ & $(3.14 \pm 0.08) \times 10^{-5}$ & $(5.88 \pm 0.07) \times 10^{-4}$ \\
7.0 & $2.66 \times 10^{-8}$ & $(3.78 \pm 0.1) \times 10^{-4}$ & $(6.30 \pm 0.03) \times 10^{-3}$ \\
8.0 & $2.66 \times 10^{-7}$ & $(3.79 \pm 0.1) \times 10^{-3}$ & $(6.14 \pm 0.06) \times 10^{-2}$
\end{tabular}

${ }^{a}$ Obtained from data in Fig. $\mathrm{S} 4 . \dagger^{b}$ The value $\left(\mathrm{mol} \mathrm{L}^{-1}\right)$ of $\left[\mathrm{OD}^{-}\right]$was calculated according to ref. 21 . perform simultaneous live cell Raman imaging of C18 SFAs and UFAs labeled with $\mathrm{H}$-/D-alkyne, the appropriate FAs were prepared. Deuterated 17-octadecynoic acid (D-3, 99\% D incorporation by ${ }^{1} \mathrm{H}$ NMR spectroscopy) was synthesized from 3 following a procedure similar to that shown in Scheme 1 (see Scheme $\mathrm{S} 1 \dagger)$. Moreover, the $\mathrm{C} \equiv \mathrm{C}$ vibrational frequency shifted from $2115 \mathrm{~cm}^{-1}$ to $1980 \mathrm{~cm}^{-1}$ upon deuteration of 3 to obtain $\mathrm{D}-3$, and the Raman peak area ratio between the $\mathrm{C} \equiv \mathrm{C}$ of $\mathrm{D}-3$ and the $\mathrm{C} \equiv \mathrm{C}$ of 3 resulted in $1: 0.013$, which is in good agreement with the NMR analysis (Fig. S5a and $\mathrm{b} \dagger$ and ${ }^{1} \mathrm{H}-\mathrm{NMR}$ ).

Next, we performed ATRI of living HeLa cells treated with 3, D-3, and alkyne-tagged oleic acid (5; Raman spectra are shown in Fig. S5c $\dagger$ ). SFA 3 and D-3 initially accumulated in LDS during the first $6 \mathrm{~h}$ of treatment, and then spread throughout the cells during the remaining treatment time (Fig. $3 \mathrm{~b}$ and c). Conversely, UFA 5 remained within the LDs during the $24 \mathrm{~h}$ treatment time (Fig. 3d). Since time-course Raman imaging of D-3 and 3 showed almost the same images (Fig. 3b and c), we concluded that deuteration has little effect on the intracellular metabolism of these labeled compounds. D/H exchange of D-3 in the lipid region was calculated; only $10 \%$ of D-3 was converted to 3 after treatment with HeLa cells for $6 \mathrm{~h}$ (Fig. 4). These results clearly indicate that $\mathrm{D}$-alkynes are viable as Raman tags, exhibiting Raman vibrational frequencies that are distinct from the H-alkynes. Simultaneous Raman imaging of

a)

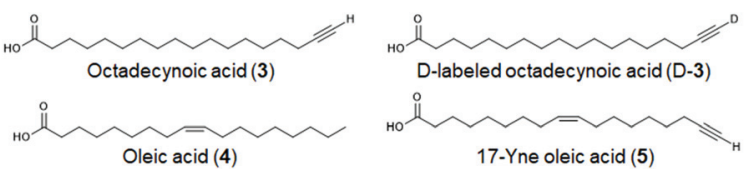

b)

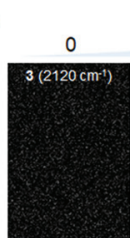

17-Yne oleic acid (5)
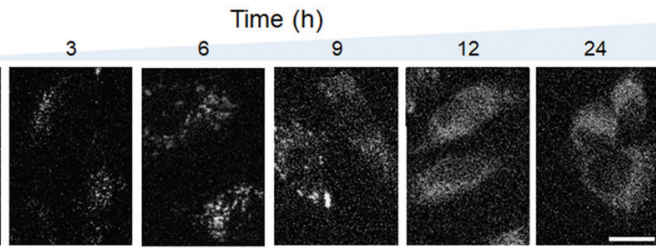

c)
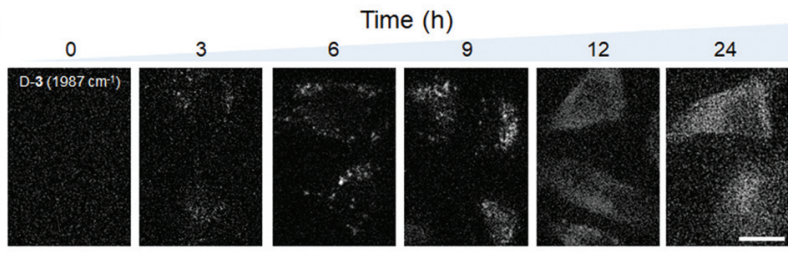

d)
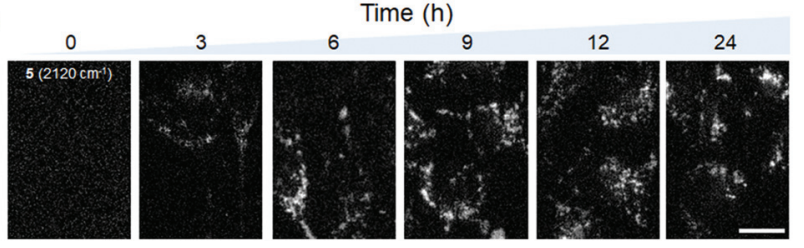

Fig. 3 (a) Structures of the C18 fatty acids. (b-d) Raman images of $\mathrm{H}$-alkynes and D-alkynes in HeLa cells treated with $100 \mu \mathrm{M}$ C18 fatty acids at various times (0-24 h). Raman images obtained from the intensity of the $C \equiv C$ signal of (b) 3 detected at $2120 \mathrm{~cm}^{-1}$, (c) D-3 detected at $1987 \mathrm{~cm}^{-1}$, and (d) 5 detected at $2120 \mathrm{~cm}^{-1}$. Scale bars are $10 \mu \mathrm{m}$. 


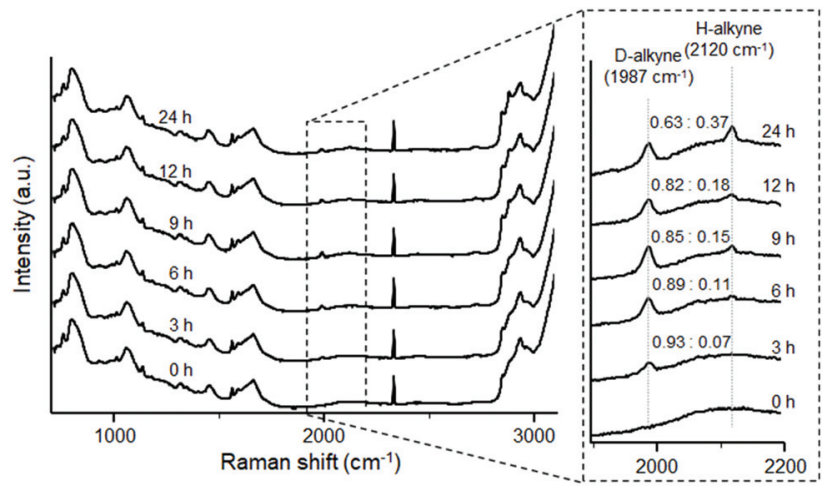

Fig. 4 Average Raman spectra of the lipid region $(20 \times 20$ pixels $)$ of ten HeLa cells treated with $100 \mu$ M D-3. Raman spectra after various incubation times (0-24 h). The Raman peak area ratios between D-alkyne and $\mathrm{H}$-alkyne signals at each treatment time are shown.

D-3 and EdU (an alkyne-tagged dT analog that is known to incorporate in nuclear DNA) ${ }^{23}$ was performed by treating HeLa cells with D-3 for $6 \mathrm{~h}$ after $22 \mathrm{~h}$ cultivation with EdU to obtain two-color Raman images (Fig. S6†).

To further demonstrate the utility of D-alkynes as Raman tags, we performed simultaneous live cell Raman imaging of D-3 and 5 at several concentration ratios (Fig. 5). At higher concentrations, both 3 and D-3 spread faster throughout the cells (Fig. S7 $\dagger$ ). Raman imaging of D-3 and 5 at a $4: 1$ molar ratio displayed clear differences in HeLa cell distribution: 5 localized in the LDs, whereas D-3 was observed in both LDs and the cytoplasm. However, at molar ratios of $1: 1$ and $2: 1$, the Raman images of D-3 and 5 appeared the same, with both FAs only detected in the LDs. Interestingly, despite the same con-

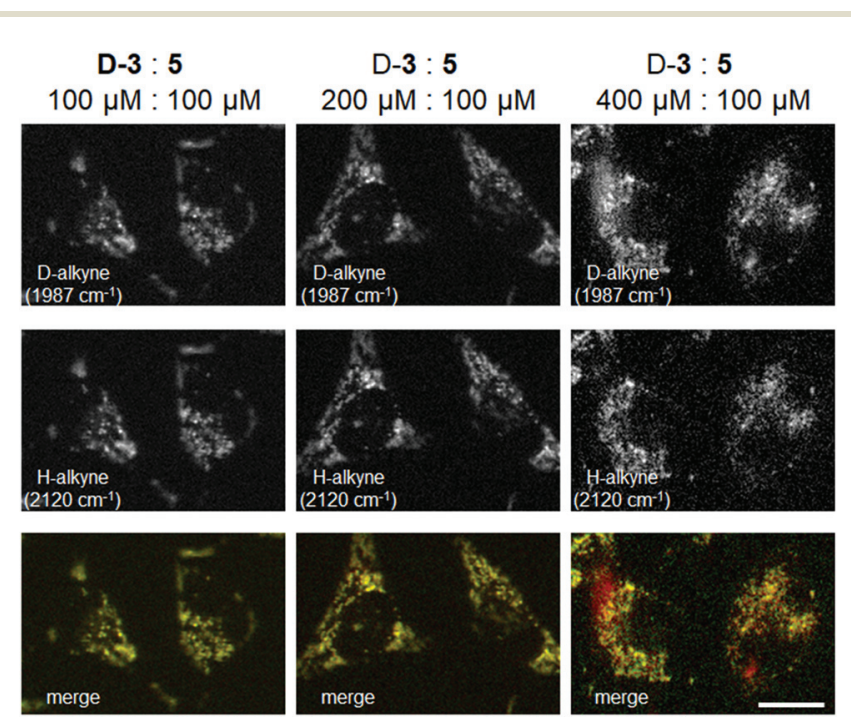

Fig. 5 Raman images of H-alkyne and D-alkyne signals in HeLa cells treated with D-3 and 5 at different dose ratios $(1: 1,2: 1$, or $4: 1)$ for $6 \mathrm{~h}$. Images were obtained from the Raman intensity of the D-alkyne detected at $1987 \mathrm{~cm}^{-1}$ and $\mathrm{H}$-alkyne detected at $2120 \mathrm{~cm}^{-1}$. Two-color Raman images are the overlapped Raman images of the D-alkyne (red) and $\mathrm{H}$-alkyne (green). Scale bars are $10 \mu \mathrm{m}$. ditions for D-3 alone and D-3 co-treatment with $5(200 \mu \mathrm{M}$ treatment for $6 \mathrm{~h}$ ), D-3 alone began to spread in cells (Fig. S7b $\dagger$ ), whereas D-3 with 5 resulted in both remaining in the LDs (Fig. 5). Previous metabolic studies demonstrated that 4 aided palmitic acid (a C16 SFA) distribution to LDs, ${ }^{24,25}$ and we surmised that 5 could also function as a guide to facilitate D-3 delivery to LDs in this experiment.

To confirm the consistency of these results (Fig. 5), Raman imaging of HeLa cells treated with SFA 3 and UFA 4 was performed under the same conditions (Fig. S8 $\dagger$ ). Since previously SFA palmitate and $\mathbf{4}$ were reported to be metabolized into triglycerides (TGs) in LDs after $6 \mathrm{~h},{ }^{24}$ most of the C-H Raman signal for the olefin detected at $3015 \mathrm{~cm}^{-1}$ was considered to be TGs derived from 4 in this experiment. ${ }^{26}$ Raman images derived from the alkyne of $\mathbf{3}$ and vinylic protons of $\mathbf{4}$ appeared the same in HeLa cells treated with $1: 1$ and $2: 1$ molar ratios, with both 3 and 4 localized in the LDs. However, at a $4: 1$ molar ratio, the Raman images differed slightly: 3 diffused into the cytosol, whereas 4 was detected only in the LDs. These results confirm that the two-color Raman images of D-3 and $\mathbf{5}$ are not artifacts. Taken together, we successfully demonstrated the utility of D-alkynes and H-alkynes as Raman tags for simultaneous Raman imaging of similar small molecules in live cells.

\section{Conclusions}

In this study, we investigated the effect of deuteration on the alkyne signal in Raman microscopy. We quantitatively measured the $\mathrm{H} / \mathrm{D}$ or $\mathrm{D} / \mathrm{H}$ exchange rate of terminal alkynes in aqueous solutions using spontaneous Raman microscopy. The H/D or $\mathrm{D} / \mathrm{H}$ exchange of terminal alkynes was dependent on its structure (whether conjugated or non-conjugated), $\mathrm{pH}$ (pD), and temperature. Furthermore, deuterated compounds are widely used in various research fields (e.g., synthetic chemistry, pharmaceutical science, and materials science) and the D-alkyne functional group is valuable for the synthesis of other deuterated functional groups, such as D-alkenes or D-alkanes, ${ }^{13,27-29}$ D-ketones, ${ }^{30}$ and D-aromatics. ${ }^{31}$ Our findings related to $\mathrm{D} / \mathrm{H}$ exchange of terminal alkynes provide further insights for the synthesis of D-labeled compounds using D-alkynes.

Furthermore, we demonstrated the utility of a deuterated non-conjugated alkyne as a Raman tag for live cell imaging, and we obtained simultaneous Raman imaging of a C18 SFA and C18 UFA in HeLa cells by monitoring the D-alkyne and $\mathrm{H}$-alkyne signals. D-alkynes and H-alkynes can serve as Raman tags to distinguish between and observe similar small molecules in cells. Live cell Raman imaging of the non-conjugated D-alkyne tag makes it possible to detect short-term accumulation and localization at slightly acidic or neutral $\mathrm{pH}$, or in the hydrophobic environment. D-alkynes are therefore promising for various applications - such as for markers of acidic organelles, as pH sensors, and as indicators to distinguish between hydrophobicity and hydrophilicity - and we expect that they will be more widely employed in diverse scientific fields in the future. 


\section{Conflicts of interest}

There are no conflicts to declare.

\section{Acknowledgements}

This work was supported by JST CREST Grant Number JPMJCR1925 (M.S.), JSPS KAKENHI Grant Number JP18K14360 (S.E.), and JSPS KAKENHI Grant Number JP20K15418 (S.E.). S. E. was supported by the Special Postdoctoral Researchers Program of RIKEN. We thank RIKEN CSRS Molecular Structure Characterization Unit for HRMS measurement.

\section{Notes and references}

1 G. J. Puppels, M. Grond and J. Greve, Appl. Spectrosc., 1993, 47, 1256-1257.

2 H. Yamakoshi, K. Dodo, M. Okada, J. Ando, A. Palonpon, K. Fujita, S. Kawata and M. Sodeoka, J. Am. Chem. Soc., 2011, 133, 6102-6105.

3 H. Yamakoshi, K. Dodo, A. Palonpon, J. Ando, K. Fujita, S. Kawata and M. Sodeoka, J. Am. Chem. Soc., 2012, 134, 20681-20689.

4 H. Yamakoshi, A. F. Palonpon, K. Dodo, J. Ando, S. Kawata, K. Fujita and M. Sodeoka, Chem. Commun., 2014, 50, 13411343.

5 L. Li, H. Wang and J.-X. Cheng, Biophys. J., 2005, 89, 34803490.

6 E. O. Potma and X. S. Xei, ChemPhysChem, 2005, 6, 77-79.

7 S. Bakthavatsalam, K. Dodo and M. Sodeoka, RSC Chem. Biol., 2021, DOI: 10.1039/d1cb00116g.

8 H. J. Lee, W. Zhang, D. Zhang, Y. Yang, B. Liu, E. L. Barker, K. K. Buhman, L. V. Slipchenko, M. Dai and J.-X. Cheng, Sci. Rep., 2015, 5, 7930.

9 M. Ueda, S. Egoshi, K. Dodo, Y. Ishimaru, H. Yamakoshi, T. Nakano, Y. Takaoka, S. Tsukiji and M. Sodeoka, ACS Cent. Sci., 2017, 3, 462-472.

10 M. Ueda, K. Hayashi, S. Egoshi, Y. Ishimaru, Y. Takaoka, H. Yamakoshi, K. Dodo and M. Sodeoka, Org. Biomol. Chem., 2018, 16, 3348-3352.

11 M. M. Gaschler, F. Hu, H. Feng, A. Linkermann, W. Min and B. R. Stockwell, ACS Chem. Biol., 2018, 13, 1013-1020.
12 Z. Chen, D. W. Paley, L. Wei, A. L. Weisman, R. A. Friesner, C. Nuckolls and W. Min, J. Am. Chem. Soc., 2014, 136, 8027-8033.

13 T. Okamura, S. Egoshi, K. Dodo, M. Sodeoka, Y. Iwabuchi and N. Kanoh, Chem. - Eur. J., 2019, 25, 16002-16006.

14 S. Mizushima, Y. Morino, Y. Kitasato and S. Nakamura, Proc. Imp. Acad., 1940, 16, 549-554.

15 H. W. Schrötter and E. G. Hoffmann, Justus Liebigs Ann. Chem., 1964, 672, 44-54.

16 K. Dodo, A. Sato, Y. Tamura, S. Egoshi, K. Fujiwara, K. Oonuma, S. Nakao, N. Terayama and M. Sodeoka, Chem. Commun., 2021, 57, 2180-2183.

17 S. P. Bew, G. D. Hiatt-Gipson, J. A. Lovell and C. Poullain, Org. Lett., 2012, 14, 456-459.

18 Y. Yabe, Y. Sawama, Y. Monguchi and H. Sajiki, Chem. Eur. J., 2013, 19, 484-488.

19 D. M. Carey and G. M. Korenowski, J. Chem. Phys., 1998, 108, 2669-2675.

20 A. K. Covington, M. Paabo, R. A. Robinson and R. G. Bates, Anal. Chem., 1968, 40, 700-706.

21 A. K. Covington, R. A. Robinson and R. G. Bates, J. Phys. Chem., 1966, 70, 3820-3824.

22 C. Matthäus, C. Krafft, B. Dietzek, B. R. Brehm, S. Lorkowski and J. Popp, Anal. Chem., 2012, 84, 85498556.

23 A. Salic and T. J. Mitchison, Proc. Natl. Acad. Sci. U. S. A., 2008, 105, 2415-2420.

24 L. L. Listenberger, X. Han, S. E. Lewis, S. Cases, R. V. Farese Jr., D. S. Ory and J. E. Schaffer, Proc. Natl. Acad. Sci. U. S. A., 2003, 100, 3077-3082.

25 Y. Shen, Z. Zhao, L. Zhang, L. Shi, S. Shahriar, R. B. Chan, G. Di Paolo and W. Min, Proc. Natl. Acad. Sci. U. S. A., 2017, 114, 13394-13399.

26 D. Fu, Y. Yu, A. Folick, E. Currie, R. V. Farese, T.-H. Tsai, X. S. Xie and M. C. Wang, J. Am. Chem. Soc., 2014, 136, 8820-8828.

27 D. Orain and J.-C. Guillemin, J. Org. Chem., 1999, 64, 35633566.

28 J. E. Baldwin and J. A. Kapecki, J. Am. Chem. Soc., 1970, 92, 4874-4879.

29 J. M. Brown and G. C. Lloyd-Jones, J. Am. Chem. Soc., 1994, 116, 866-878.

30 J. Dheur, M. Sauthier, Y. Castanet and A. Mortreux, Adv. Synth. Catal., 2007, 349, 2499-2506.

31 R. N. Nair, P. J. Lee and D. B. Grotjahn, Catalysis, 2010, 53, 1045-1047. 